Eixo Temático: Desenvolvimento de Estratégias Didáticas

\title{
ET-07-010 \\ A LUDICIDADE E SUA MEDIAÇÃO NAS RELAÇÕES INTERPESSOAIS PARA O TRABALHO DE TEMAS “TABUS”: EXPERIÊNCIA DE PIBIDIANOS
}

Elivandia da Silva Ferreira ${ }^{1}$, Iasmim Dantas dos Santos e Santos ${ }^{1}$, Mariana Nepomuceno Lima ${ }^{1}$, Eltamara Souza da Conceição², Maria José Dias Sales³

${ }^{1}$ Graduandas em Ciências Biológicas e bolsistas PIBID-UNEB/CAPES.

2Orientadora PIBID-UNEB/CAPES. E-mail: elta_mara@yahoo.com.br;

3Professora Escola Estadual dos Rodoviários. E-mail: maria_uneb@yahoo.com.br.

Universidade do Estado da Bahia. Programa Institucional de Bolsa de Iniciação à Docência. Bahia.

http://dx.doi.org/10.21472/congrebio2016.et-07-010

\section{RESUMO}

Diante da necessidade de se adotar novas metodologias que aproximem o educando do professor, os jogos didáticos em sala de aula surgem como uma atividade lúdica que estimula o interesse do educando, ajuda em suas novas descobertas e contribuem efetivamente em seu potencial, tornando a sala de aula mais agradável e atraente. Esse trabalho tem como objetivo relatar a experiência da aplicação de um jogo sobre temas abordando Sexo e Sexualidade, desenvolvido e aplicado pelos licenciandos de Ciências Biológicas da Universidade do Estado da Bahia (Campus II, Alagoinhas-BA), bolsistas do Programa Institucional de Bolsa de Iniciação à Docência, sobre a importância da ludicidade na mediação das relações interpessoais para o trabalho de temas "tabus", como Orientação Sexual. O trabalho relatado em questão se trata de um jogo que envolvem perguntas e situações relevantes para a educação sexual, que foi desenvolvido pelos bolsistas ID e aplicado com estudantes do oitavo ano do ensino fundamental. No final do trabalho foi possível concluir que, através da execução e das observações da turma durante a aplicação do jogo, os objetivos traçados foram atingidos e os educandos conseguiram interagir e trocar conhecimentos entre eles, e com os bolsistas ID. (Programa Institucional de Bolsa de Iniciação à Docência - PIBID).

Palavras-chave: Ensino; Jogos; Educação sexual.

\section{INTRODUÇÃO}

A aula expositiva é a modalidade didática mais tradicional de ensino. Para Costoldi e Polinarski (2009), a grande maioria dos professores possuem tendência em adotar tal método por receio de inovar, sendo esta prática muito estabelecida no sistema educacional brasileiro. Como sugere Kishimoto (1996), os docentes devem rever a utilização de propostas pedagógicas, passando praticar aquelas que atuem nos componentes internos da aprendizagem, já que estes não podem ser ignorados quando o objetivo é a apropriação de conhecimentos por parte do educando.

Pozo (2003), diz que as finalidades do sistema educacional são tornar os futuros cidadãos aprendizes mais flexíveis, eficazes e autônomos. Mas para isso é necessária a utilização de recursos didáticos, ou seja, materiais utilizados em sala com o intuito de facilitar o processo de ensino-aprendizagem. Deste modo, o professor deve possuir objetivos pedagógicos determinados sendo necessário o apoio estrutural da escola, garantindo os materiais que serão utilizados para as atividades ocorrerem de forma satisfatória. 
Os recursos didáticos aproximam os educandos da teoria, permitindo assim uma maior assimilação do conteúdo e, consequentemente, traz uma aprendizagem mais efetiva. Além disso, com a utilização de recursos didático-pedagógicos, podem-se preencher as lacunas que o ensino tradicional geralmente deixa (COSTOLDI e POLINARSKI, 2009), desde que sejam apropriados. Na literatura didática existem vários meios e recursos que podem ser utilizados pelos professores, um deles é o jogo didático que, segundo Kishimoto (1996), é o eixo que conduz a um conteúdo didático específico, resultando em um empréstimo da ação lúdica para a aquisição de informações.

No meio educacional, a inserção de jogos demorou de ser aceita, devido a sua associação com o prazer. Sendo primeiramente usados somente devido ao seu aspecto lúdico. Mas, com o decorrer do tempo, passaram a ser aplicados em atividades para formação do caráter e da personalidade. Atualmente, mesmo depois da divulgação dos benefícios trazidos pela inserção dos jogos didáticos em sala de aula, poucos professores os reconhecem como uma atividade facilitadora da aprendizagem significativa e de conhecimentos específicos (CAMPOS et al., 2008).

A ludicidade, através do jogo como estratégia de ensino, ganhou um espaço na aprendizagem na medida em que propõe estimulo ao interesse do educando, ajuda a construir suas novas descobertas, desenvolve e enriquece sua personalidade; neste processo, o professor atua como condutor, estimulador e avaliador da aprendizagem, aproximando os estudantes do conhecimento científico (CAMPOS et al., 2008). Ainda possibilita a interpretação dos dados fornecidos de maneira mais rápida, trabalha as relações interpessoais entre professores/alunos, torna a sala de aula atraente e o mais importante, torna os educandos agentes na construção do próprio saber. $\mathrm{O}$ jogo didático se faz necessário, principalmente nos componentes curriculares que incluem conhecimentos ditos “abstratos”. Pois, na maioria das vezes, a difícil compreensão dos conteúdos faz com que a aprendizagem se dê por memorização e não se processe de forma efetiva.

A orientação sexual, de acordo com os PCNs, é um tema transversal a ser trabalhado ao longo de todos os ciclos de escolarização. Por isso não se descarta o uso de metodologias lúdicas para ser discutido. Devido ao tabu criado em torno do assunto, é necessário tratá-lo de forma a deixar os estudantes serenos, para que possam esclarecer suas dúvidas, refletir e debater, num ambiente acolhedor e respeitoso. Nesse sentido, é extremamente relevante a colaboração da família, ao educar, para que a escola possa orientar exitosamente seus educandos.

\section{OBJETIVOS}

Esse trabalho possui como objetivos relatar a experiência da aplicação de um jogo sobre temas abordando Sexo e Sexualidade, desenvolvido e aplicado pelos licenciandos de Ciências Biológicas da Universidade do Estado da Bahia, Campus II, de Alagoinhas-BA (bolsistas ID do projeto interdisciplinar Biologia/Matemática), e discutir a importância da ludicidade na mediação das relações interpessoais para o trabalho de temas “tabus”, como Orientação Sexual.

\section{METODOLOGIA}

O trabalho foi realizado numa turma de $8^{\circ}$ ano da Escola Estadual dos Rodoviários, no município de Alagoinhas-BA. O jogo em questão, intitulado "Vamos opinar?", aborda temas relevantes para a educação sexual de adolescentes. Foi desenvolvido com configurações semelhantes às do jogo conhecido como "Verdade ou consequência", conhecido pelos adolescentes, que, segundo conhecimento popular, consiste numa roda de participantes que giram uma garrafa ou outro objeto de formato similar, com duas extremidades diferentes entre si, de forma que ao fim do giro, o objeto aponte para dois participantes para responder uma pergunta ou aceitar um desafio. 
Os participantes do jogo em questão foram os alunos de uma faixa etária entre 14 a 16 anos, os quais se organizaram formando um círculo, sentados em cadeiras. Um dos participantes girava a garrafa, de tal maneira que ao fim do giro, a direção da pessoa que extremidade principal da garrafa apontasse, seria aquela que iria retirar um cartão que continha uma pergunta/problema a resolver, de dentro da caixa. Estas perguntas já haviam sido previamente formuladas pelos bolsistas de Iniciação à Docência (ID). Os cartões eram retirados de uma caixa e as perguntas eram sobre situações corriqueiras relacionadas à sexualidade na adolescência. Ao retirar o cartão da caixa, o educando tinha que tentar opinar sobre o tema, com ajuda dos demais colegas, gerando uma discussão e uma troca de informações.

Assim, o objetivo era envolver os educandos o suficiente para que abordassem amplamente o tema, de maneira relevante, para um melhor entendimento sobre as questões concernentes à educação sexual. Diante desta perspectiva, os educando eram estimulados a responder as perguntas do jogo e os bolsistas ID, enquanto mediadores, não respondiam as questões nem influenciavam nas respostas destes, mas os orientavam, junto à professora regente para que as dúvidas fossem dirimidas e os equívocos fossem sanados. Assim, mesmo que no primeiro momento afirmassem não serem capazes de responder às perguntas, regente e bolsistas ID buscavam questioná-los de outra forma, em uma linguagem apropriada, apresentando a situação de uma maneira diferente. Assim, junto com eles, buscou-se chegar a uma resposta e a partir daí, proceder a mediação e construção do conhecimento, bem como ressignificação dos conceitos antes mal interpretados.

\section{RESULTADOS E DISCUSSÕES}

Tendo em vista a relevância de abordar a sexualidade no âmbito escolar, é notória a necessidade da criação de novas metodologias para o enfoque do tema em questão e é dentro desta perspectiva que o jogo colaborou para sanar os problemas relacionados a essa questão, porque de forma lúdica e divertida como a atividade ocorreu, verificou-se a serenidade, que não é muito comum em turmas de adolescentes, ao tratar de temas desse tipo

Segundo os PCNs é de fundamental importância que os estudantes tenham compreensão do corpo como um todo e da saúde humana. O documento deixa clara a necessidade de se reconhecer as dúvidas dos estudantes, as representações que eles já fazem sobre os sistemas reprodutores humanos masculino e feminino e os aspectos psicológicos envolvidos, por intermédio do que falam, escrevem ou desenham.

Por ser esse um tema de grande importância, mas que traz algumas questões atreladas, os PCNs afirmam que:

A discussão sobre sexualidade com adolescentes é tão emocionante quanto a fase efervescente da vida em que se encontram. Apesar de alguns julgarem que a discussão sobre sexualidade está se tornando uma coisa normal, muitos jovens ainda sentem vergonha e medo de discutir esse assunto.

Diante da complexidade de se abordar o tema, a todo momento buscou-se criar um ambiente livre de julgamentos e pré-conceito, que propiciasse essas discussões. Não havia a intenção de expor a vida intima dos estudantes. Por esse motivo, o que estava escrito nos cartões presentes na caixa não eram perguntas diretas, e sim situações que permitiam ao educando discorrer tranquilamente sobre o assunto e tirar dívidas, caso as possuíssem. Todos tinham a liberdade de opinar sobre o tema, mesmo que não fosse o jogador da vez, e essa discussão era estimulada pelos bolsistas ID. Assim, percebeu-se o quanto o jogo contribuiu para o processo de ensino e aprendizagem e despertou o interesse dos estudantes para questões não muito bem esclarecidas até então. Todos mostraram interesse em opinar, tirar dúvidas, para comprovar aquilo que ouve através de outros meios de educação não formal, como através da mídia. Isso foi feito de uma forma tranquila, sem brincadeiras indiscretas ou julgamentos inconvenientes. 
Assim percebeu-se com o jogo, o que cita Fonseca e Scochi (1999), quando diz que o jogo ajuda a construir novas descobertas, desenvolve e enriquece a personalidade, além de simbolizar um instrumento pedagógico que leva ao professor a condição de condutor, estimulador e avaliador da aprendizagem. Assim percebeu-se, durante a aplicação do jogo, que os educandos conseguiam formular conceitos e definições para explicar a situações problemas e, para isso, foi necessário apenas incentivo dos bolsistas ID e da professora, para que conseguisse formular suas próprias opiniões.

A forma de lidar com determinados tabus gera grandes dificuldades dos profissionais da educação para executar seu trabalho. Uma vez que temas que possuem esse caráter têm que ser abordados corriqueiramente nas aulas de Ciências, isso ainda é uma questão de difícil resolução no ensino de Ciências. Para os bolsistas ID, enquanto professores em formação, o contato com a escola e a vivência de experiências como estas são enriquecedoras e altamente relevantes para sua plena qualificação profissional. Os quais puderam vencer dificuldades que talvez não conseguissem sem esse tipo de experiência e apenas cumprindo com as formalidades dos estágios obrigatórios planejados na universidade. Assim, pode dizer que a atividade foi muito rica para todas as partes, educandos, bolsistas ID e professora regente. Porque permitiu a interação incomum nas relações escolares e facilitou o trabalho de tema tão importante, além da partilha de percepções diversas. A necessidade de se interagir a partir de percepções comuns do mundo que nos cerca ou de um contexto mental comum é típica de qualquer interação humana (EDWARDS e MERCER, 1987 apud MOITA LOPES, 1996).

Por se tratar de um jogo, onde na visão dos estudantes não estão sendo avaliados e não há cobranças, foi visível maior espontaneidade nas formas de expressão. Os estudantes opinavam sem medo de errar, sentimento muito comum nas turmas dessa faixa etária. Assim, arriscavam e tentavam construir uma resposta em conjunto.

Antunes (2003) afirma que:

O jogo é o mais eficiente meio estimulador das inteligências, permitindo que o indivíduo realize tudo que deseja. Quando joga, passa a viver quem quer ser, organiza o que quer organizar, e decide sem limitações. Pode ser grande, livre, e na aceitação das regras pode ter seus impulsos controlados. Brincando dentro de seu espaço, envolve-se com a fantasia, estabelecendo um gancho entre o inconsciente e o real. Enfim, foi possível uma discussão saudável e em clima tranquilo e leve e que possibilitou grandes contribuições na construção de novos conhecimentos.

\section{CONCLUSÃO}

Ao final do trabalho, concluímos que, através da execução e das observações da turma durante a aplicação do jogo, os objetivos traçados foram atingidos. Assim, os educandos conseguiram interagir e trocar conhecimentos entre eles, com os bolsistas ID e a professora supervisora. Isto evidencia a importância deste para a interação entre todos e que este foi altamente relevante para o compartilhamento do conhecimento, significativo para o alcance da autonomia cidadã e ressignificação de conceitos destorcidos sobre esse tema tabu. Esta vivência foi de grande importância para nossa formação enquanto futuros docentes, uma vez que permitiu-nos observar como a ludicidade deve ser valorizada como instrumento que motive a participação bem como maior aproximação entre docentes e discentes.

\section{AGRADECIMENTOS}

Ao PIBID financiado pela Coordenação de Aperfeiçoamento de Pessoal do Nível Superior (CAPES), pela oportunidade de atuação nas escolas da região e pela concessão de bolsas aos envolvidos. A Escola Estadual dos Rodoviários, a professora supervisora Jeane 
Mendes Serravalle e a professora colaboradora Maria José Dias Sales, pelo apoio e auxilio para a realização desse trabalho.

\section{REFERÊNCIAS}

BRASIL. Ministério da Educação. Secretária de Educação Fundamental. Parâmetros curriculares nacionais: terceiro e quarto ciclos do ensino fundamental: Ciências Naturais. Secretaria de Educação Fundamental, Brasília, 1998.

CAMPOS, L. M. L.; BORTOLOTO, T. M.; FELÍCIO, A. K. C. A produção de jogos didáticos para o ensino de ciências e biologia: Uma proposta para favorecer a aprendizagem. 2008. Disponível em: <http://www.unesp.br/prograd/PDFNE2002/aproducaodejogos.pdf >. Acesso em: 15 abr. 2016.

COSTOLDI, R.; POLINARSKI, C. A. Utilização de recursos didático-pedagógicos na motivação da aprendizagem. I Simpósio Internacional de Ensino e Tecnologia. 2009.

KHOURY, Z. A. A simulação global como atividade mediadora na aprendizagem do vocabulário em aulas de francês língua estrangeira: criar para aprender e interagir. São Paulo: Faculdade de Filosofia, Letras e Ciências Humanas, Universidade de São Paulo, 2008. (Tese de doutorado).

KISHIMOTO, T. M. Jogo, brinquedo, brincadeira e a educação. São Paulo: Cortez, 1996.

LIRA-DA-SILVA, R. M.; LIRA-DA-SILVA, J. R.; MISE, Y. F.; DORES, J. L. R.; ARAÚJO, B. R. N. Ludicidade e Ciência: Produção e Divulgação de Jogos Sobre Ciências em um Espaço de Ensino Não-Formal. In: ENCONTRO NACIONAL DE PESQUISA EM EDUCAÇÃO EM CIÊNCIAS, 8, CONGRESO IBEROAMERICANO DE INVESTIGACIÓN EN ENSEÑANZA DE LAS CIENCIAS, $1 . \quad$ Rio de Janeiro, 2011. Disponível em: $<$ http://www.nutes.ufrj.br/abrapec/viiienpec/resumos/R0273-7.pdf>. Acesso em: 16 abr. 2016.

LISBOA, M. A importância do lúdico na aprendizagem, com auxílio de jogos. Disponível em: <http://brinquedoteca.net.br/?p=1818>. Acesso em: 16 abr. 2016.

POZO, J. I. Aprendizagem de conteúdos e desenvolvimento de capacidades no ensino médio. In: Coll, C. et.al. Psicologia da aprendizagem no Ensino Médio. Porto Alegre: Artmed. 2003. 